\title{
The Truth-Seeking and Open-Mindedness of Pre-Service Mathematics Teachers in the Solution of Non-Routine Problems
}

\author{
Dian Kurniati \\ Dr. Candidate State University of Malang, Lecture in Department of Mathematics \\ Education, University of Jember, Indonesia, dian.kurniati.1703119@students.um.ac.id

\section{Purwanto} \\ Prof., Postgraduate of Mathematics Education, State University of Malang, Indonesia, \\ purwanto.fmipa@um.ac.id
}

\section{Abdur Rahman As'ari}

Dr., Senior Lecturer, Corresponding author, Postgraduate of Mathematics Education, State University of Malang, Indonesia, abdur.rahman.fmipa@um.ac.id

\section{Dwiyana}

Ph.D., Senior Lecturer, Postgraduate of Mathematics Education, State University of Malang, Indonesia, dwiyana.fmipa@um.ac.id

Whether one engages in truth-seeking and whether he or she is open-minded are indicative of his or her critical behavior when responding to problems at hand. This research sought to determine the behavioural tendencies of pre-service mathematics teachers in the solution of non-routine problems based on the indicators of truth-seeking and open-mindedness. It was qualitative in nature, with an exploratory descriptive methodology. The participants in the research comprised of 15 pre-service mathematics teachers. The data were collected through tests, direct observation, and interviews. To guarantee the validity and reliability of the research, the triangulation technique was used. It entailed comparing the direct observation results with the results of the test and the interviews. The findings and conclusions were reached and the results indicated that all the pre-service mathematics teachers had not yet attained critical thinking dispositions pertinent to truth-seeking. The participants did not investigate the truth behind the information provided, and they tended to answer questions directly.

Keywords: truth-seeking, open-mindedness, pre-service mathematics teacher, nonroutine problem, mathematics 


\section{INTRODUCTION}

Critical thinking is one of the pivotal skills that students and teachers develop. The educational expectations in the 21 st century, which stipulate that four capabilities should be developed in students - creative thinking, critical thinking, communication, and collaboration, usually known as the 4Cs-reinforce this premise (Dilley, Kaufman, Kennedy, \& Plucker, 2015). The emphasis is also in line with the graduate competency standards that the Indonesian government has formulated; these call for six capabilities at the primary and secondary education levels, and one of them is critical thinking. Furthermore, critical thinking is one of the five most frequently researched thinking skills in the world and is assessed with the aim of tracking individuals' success in the future (Akınoğlu \& Karsantık, 2016).

Critical thinking is reflective and rational thinking that focuses on the process of determining what to do or to believe (Ennis, 1996). One component of critical thinking is disposition (Rivas \& Saiz, 2016; Turabik \& Gün, 2016; Chukwuyenum, 2013). One's critical thinking disposition is his or her tendency to engage in a decision-making process when working on a problem. There are seven components of the critical thinking disposition, namely, truth-seeking, open-mindedness, analyticity, systematicity, self-confidence, inquisitiveness, and maturity (Darby \& Rashid, 2017; Aizikovitsh-Udi \& Cheng, 2015; Bakir, 2015; Karagöl \& Bekmezci, 2015; Biber, Tuna, \& Incikabi, 2013; Lampert, 2007). One's critical behaviour when responding to a problem should be based on at least two critical thinking disposition components, namely truth-seeking and open-mindedness (Ordem, 2017; Dwyer, Hogan, \& Stewart, 2014). Truth-seeking is the behavioural tendency to aim at the best understanding of a particular situation (Insight Assessment, 2017). Open-mindedness denotes the tendency to tolerate others' potentially different opinions (Insight Assessment, 2017). Furthermore, based on the definition of critical thinking which Ennis (1996) proposed, an individual is said to be a critical thinker if he or she tends to engage in truth-seeking and to be open-minded. This is because truth-seekers always think consciously and reflectively to control and investigate the truth of problems at hand. Hence, they can determine the best strategies and make apt decisions in the solution of problems (Choy \& Oo, 2012). As for openminded people, they always think rationally because they can accept all possible logical views and focus on the truth of a solution (Stanovich, 2016).

In reality, the truth-seeking and open-mindedness components are still very minimally prevalent among mathematics students (Akgun \& Duruk, 2016; Biber et al., 2013; Lampert, 2007). Therefore, it is necessary to familiarize these students, pre-service mathematics teachers, with the mastery of the critical thinking disposition, focusing on truth-seeking and open-mindedness. In an attempt to familiarize students with the disposition of critical thinking, researchers have been investigating this behavioural tendency (Arsal, 2017; Ajzen, 1991), and the factors underlying the critical thinking disposition (Akınoğlu \& Karsantık, 2016; Facione, 2000) play a crucial role. The present research is focused on investigating the truth-seeking and open-mindedness of pre-service mathematics teachers, which emerged when they attempted to solve nonroutine problems. 
Several studies were conducted to investigate pre-service teachers' critical thinking disposition or their critical thinking disposition based on gender, school quality, problem-solving skills, emotional intelligence skills, and teacher quality (Turabik \& Gün, 2016; Biber et al., 2013). Several of these studies suggested that gender, school quality, and emotional intelligence had no bearing on the critical thinking disposition (Akgun \& Duruk, 2016; Kalelioğlu \& Gülbahar, 2014; Lampert, 2007). By contrast, other studies suggested that a positive relationship existed between problem-solving ability and the critical thinking disposition (Aybek, 2016; Cooke, 2015; Karagöl \& Bekmezci, 2015; Temel, 2014; Emir, 2013). Several types of problem-solving can be used to investigate the critical thinking disposition of students or pre-service teachers in the solution of mathematics problems, i.e., open-ended problems, illogical problems, problem-solving, authentic problems, non-routine problems, daily issues, and incomplete problems (As'ari, Mahmudi, \& Nuerlaelah, 2017; Cheng \& Wan, 2017; Darby \& Rashid, 2017). Some questions are designed to appear wrong or incomplete; therefore, they require pre-service mathematics teachers to deploy higher-order problem-solving and interpretation abilities (Dündar \& Yaman, 2015). Hence, when solving non-routine problems, pre-service teachers should master the ability to answer complex problems using systematic procedures, good reasoning ability, correct decision-making ability, and higher-order thinking skills.

The research aims to determine the behavioural tendencies of pre-service mathematics teachers in the solution of non-routine problems based on the indicators of truth-seeking and open-mindedness. Two research questions are under investigation. First, how are the behavioural tendencies of pre-service mathematics teachers in the solution of nonroutine problems based on the indicator of truth-seeking? Second, how are the behavioural tendencies of pre-service mathematics teachers in the solution of nonroutine problems based on the indicator of open-mindedness? The present research strives to make the following contributions. First, it aims to identify early truth-seeking before the resolution of non-routine problems and after the resolution of non-routine problems. Second, it focuses on identifying open-mindedness when pre-service teachers attempt to solve non-routine problems. Third, it probes types of non-routine problems which are essential to identifying the emergence of truth-seeking and open-mindedness. Fourth, knowing the characteristics of pre-service mathematics teachers who are truthseekers or not truth-seekers so that we can finding the mathematics learning model that is appropriate for each pre-service mathematics teachers. Fifth, knowing the tendency of the disposition of critical thinking of the pre-service mathematics teachers when solving the non-routine problems.

\section{REVIEW OF LITERATURE}

The critical thinking disposition is one's behavioral tendency in relation to the deployment of critical thinking (Ennis, 1996). Furthermore, the critical thinking disposition indicates flexible thinking, the value of openness, dogmatism, categorical thinking, the identification of beliefs, counterfactual thinking, and absolutism (Ige, 2017). Before acting, a critical thinker thinks of everything that should be done. Therefore, the critical thinking disposition plays an important role in the development of 
one's critical thinking skills. One's thinking process cannot be accurate when effective and desirable conditions are absent (Ajzen, 1991). An inadequate attitude or disposition can affect the ability to engage in careful observation and analysis, resulting in improper decision-making. Furthermore, some indicators highlight the critical thinking disposition. People who have the critical thinking disposition tend to ask for clarity, work diligently, collect information diligently, prioritize rationality, care about impacts, and emphasize precision (Facione, 2000). The characteristics of a person with a critical thinking disposition are truth-seeking, open-mindedness, analyticity, systematicity, selfconfidence, inquisitiveness, and maturity (Insight Assessment, 2017). The characteristics of people with critical thinking dispositions when dealing with the process of solving problems or answering questions are (a) clarifying the details related to a problem, (b) diligently seeking relevant information, (c) being rational in determining and applying criteria, (d) solving complex problems using a clear procedure, (e) focusing on the main problem, (f) never giving up, and (g) carefully taking into account the subject and situation (Nugroho, Nusantara, As'ari, Sisworo, Hidayanto, \& Susiswo, 2018). Furthermore, one's actions are considered critical only if they achieve at least two components of the critical thinking disposition: truth-seeking and open-mindedness (Ordem, 2017; Dwyer et al., 2014). Therefore, the mastery of the truth-seeking and open-mindedness indicators is, at least, indicative of the characteristics of people with a critical thinking disposition.

Truth-seeking is the consistent habitual tendency to aim for the best understanding of a particular situation, putting acute emphasis on evidence and reasoning, even for truths that have been acknowledged; questioning one's established belief; and pondering important details (Insight Assessment, 2017). Ennis (1985) stated that truth-seekers always (1) sought clear statements about their theories or questions, (2) sought or paid attention to arguments, (3) tried to find the best information, (4) used credible sources and made clear reference to them, (5) looked for as much precision as possible in justification of a material, (6) tried to remain focused on the main points, and (7) consistently bore in mind original and/or basic problems. Based on these two perspectives, truth-seekers are accustomed to controlling and checking the truth of problems so that they can determine the best strategy and make apt decisions in the solution of problems. Therefore, truth-seekers are used to reflective thinking when solving problems and are consciously used to controlling and checking the truth of problems so that they can determine the best strategies and make decisions in the solution of problems (Choy \& Oo, 2012).

Open-mindedness is a tendency to allow others to express their possibly different points of view and the willingness to demonstrate tolerance for different opinions (Insight Assessment, 2017). Ennis (1985) asserted that an open-minded person was characterized by (1) being an open thinker, (2) defending his own opinion and only changing opinions when evidence and reason were sufficiently convincing, and (3) aiming at as much precision as possible as justification when making decisions concerned with determining solutions to problems. Therefore, people who are accustomed to open-mindedness always think rationally because they can accept all possible different logical views and focus on the truth of a solution (Stanovich, 2016). 
Truth-seeking and open-mindedness can be observed in prospective mathematics teachers when they are solving non-routine problems, especially illogical problems and incomplete problems. According to As'ari et al. (2017), illogical problems are also called ill-defined problems. Ill-defined problems are those which contain ambiguous information (As'ari et al., 2017; Hocking \& Vernon, 2017) and contradictory information (As'ari et al., 2017). Incomplete problems are problems that contain incomplete information, thus calling for the completion of the information in question before problem-solving (As'ari et al., 2017; Ohlsson, 2012). The indicators of truthseeking and open-mindedness in the process of solving illogical problems and incomplete problems in this research are those which Insight Assessment (2017) and Ennis (1985) formulated. The indicators are presented in Table 1.

Table 1

The indicators of Truth-Seeking and Open-Mindedness in the Process of Solving Illogical Problems and Incomplete Problems

\begin{tabular}{llll}
\hline & Illogical Problems & \multicolumn{2}{l}{ Incomplete Problems } \\
\hline Truth- & $\begin{array}{l}\text { 1. Investigating the truth behind a } \\
\text { problem (a) before, (b) during, and } \\
\text { (c) after solving the problem. }\end{array}$ & $\begin{array}{l}\text { 1. } \\
\text { Revising and changing an illogical } \\
\text { problem into a logical one. }\end{array}$ & $\begin{array}{l}\text { Invating the truth behind a } \\
\text { problem (a) before, (b) during, and } \\
\text { (c) after solving the problem. } \\
\text { Adding unknown information to } \\
\text { complete the problem. }\end{array}$ \\
\hline $\begin{array}{l}\text { Open- } \\
\text { Mindedness }\end{array}$ & $\begin{array}{l}\text { 1. } \begin{array}{l}\text { Discussing with peers who have a } \\
\text { similar answer or a different one } \\
\text { and determining the right answer. }\end{array} \\
\text { 2. } \begin{array}{l}\text { Accepting peer's or lecturer's } \\
\text { logical opinion regardless of } \\
\text { differences. }\end{array}\end{array}$ & $\begin{array}{l}\text { Discussing with peers who have a } \\
\text { similar answer or a different one } \\
\text { and determining the right answer. } \\
\text { Accepting peer's or lecturer's } \\
\text { logical opinion regardless of } \\
\text { differences. }\end{array}$ \\
\hline
\end{tabular}

\section{METHOD}

\section{General Background of Research}

This research was qualitative in nature and employed an exploratory descriptive method. It was projected to describe the behavioural tendency of pre-service mathematics teachers in the solution of non-routine problems based on the indicators of truth-seeking and open-mindedness. The design was operationalized because qualitative descriptive research constituted a design that was aimed at describing, combining, analyzing, and interpreting the situation of an individual, institution, or group (Akınoğlu \& Karsantık, 2016).

\section{Participants in the Research}

The research involved 80 mathematics students in their seventh semester at the University of Jember, East Java, Indonesia. Out of these 80 students, 15 were chosen as the participants in this study using a purposive sampling method (Avci, Eren, \& Kapucu, 2016) that was based on the following considerations: 1) the students had taken a microteaching course and were engaged in their pre-service teaching during the research, 2) the decision was also based on the students' consent to be selected as research participants, and 3) the students could communicate their thoughts through both 
speech and writing. The test was done on January 6, 2018, and the results helped in the investigation of the truth-seeking and open-mindedness the students actuated during the solution of non-routine problems, especially illogical and incomplete problems.

\section{Instruments}

The instruments used in this research were 1) a test which comprised three non-routine problems, 2) an observation sheet for observing truth-seeking and open-mindedness during non-routine problem-solving, and 3) a guided semi-structured interview for confirming the behavioural tendencies of the participants when solving given problems. The content validity of the test, the observation sheet, and the guided semi-structured interview were addressed by involving various professors across related disciplines. This consultation resulted in a series of substantive changes to the test, observation sheet, and semi-structured interview.

\section{Data Collection Methods}

Data in this research were collected through testing, direct observation, and interviewing. The test was given to determine the characteristics of the research subjects' responses and attitudes; it employed the indicators of truth-seeking and openmindedness. All the subjects were required to complete three problems; they were three non-routine questions that comprised one incomplete question and two illogical questions. The three non-routine problems follow: First, find the value of $a, b, c$ where $a, b, c \in A=\{1,3,5,7,9,11,13,15\}$ and you can do a repetition of that number such that $a+b+c=30$. Second, if $0<a<b, a^{2}+b^{2}=-4 a b$, then find the value of $\frac{b-a}{a+b}$. Third, find the inverse of the function $f(x)=x^{2}$.

During the test, the researchers also observed and recorded the participants' behaviour when solving non-routine questions then classified their truth-seeking and openmindedness contours using an observation sheet. The last data collection method was the in-depth interview. Each interview was recorded using a video, and the participants' written test results were collected. To ensure the validity and reliability of the research, data analysis was performed by triangulation: the data from the direct observations was displayed and compared with the participants' written test data and the interviews (Golafshani, 2003). This was carried out to determine the participants' behavioural tendencies when solving illogical problems and incomplete problems based on the indicators of truth-seeking and open-mindedness. The data resulting from the triangulation were analyzed.

\section{Data Analysis}

The data were analyzed through the application of data reduction and data presentation, leading to the study's findings and conclusion. In the first stage, the data reduction dealt with including pertinent variables which were in line with the research objectives and 
excluding unnecessary variables. The second stage, data presentation, was related to classifying the reduced data into two groups, namely, (1) the behavioural tendencies of the teachers in the solution of non-routine problems based on the indicator of truthseeking and (2) the behaviour of the pre-service teachers in the solution of non-routine problems based on the indicator of open-mindedness. The final stage entailed drawing conclusions based on the findings and the data presentation.

\section{FINDINGS}

\section{The Truth-Seeking and Open-Mindedness of the Pre-Service Mathematics Teachers When Solving Non-Routine Problem Number 1}

The research participants were given the first non-routine problem, which was an illogical problem. The problem was formulated as follows: Find the value of $a, b, c$ where $a, b, c \in A=\{1,3,5,7,9,11,13,15\}$ and you can do a repetition of that number,

such that $a+b+c=30$.

Five pre-service teachers worked directly on the first question by experimenting to substitute three numbers $a, b, c \in A$ in such way as to generate a sum of 30 . After experimenting, they concluded that there were no numbers $a, b$, and $c \in A$ that met the conditions set. A sample of the participants' answers is presented in Figure 1.

The five participants determined that the given problem was erroneous without providing any logical reason because their premise was solely based on trial and error. In this case, the five pre-service teachers did not confirm or investigate the truth behind the question before working on it. Furthermore, they did not seek different perspectives or search for information about the problem by looking for evidence and the correct argument to determine the truth of their conclusions

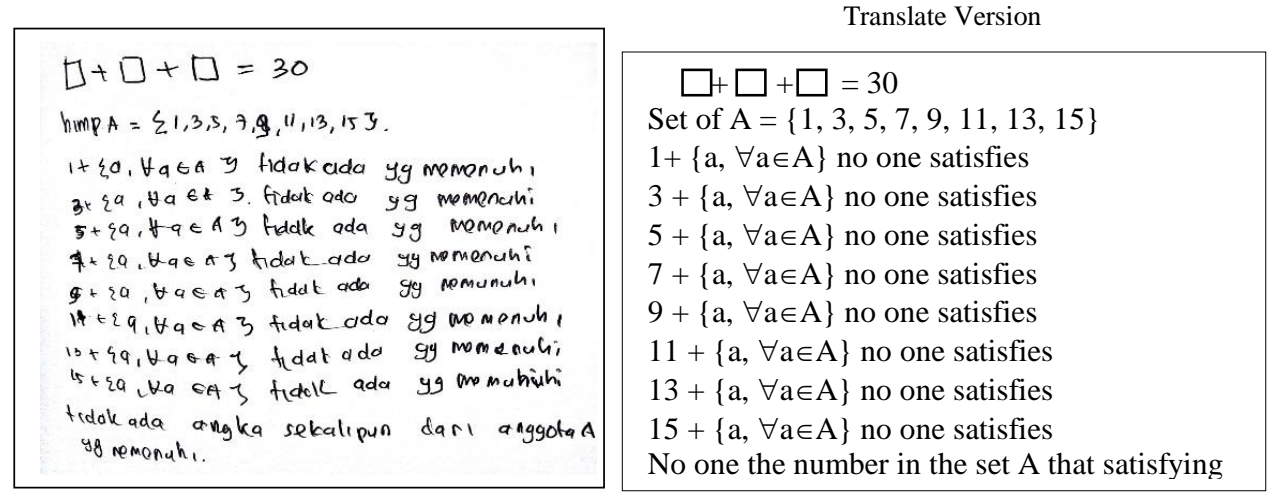

Figure 1

One of Five Samples of the Pre-Service Mathematics Teachers' Answers to Question Number 1 
This sample answer is slightly different from those of the other eight research participants. The eight participants immediately worked on the problem without any initial analysis of the truth behind the problem, but they found evidence and engaged in logical reasoning to determine that the given question was illogical. In the beginning, the participants directly responded to the question given by experimentally substituting three numbers $\mathrm{a}, \mathrm{b}$, and $\mathrm{c}$, which were members of $\mathrm{A}$, in such a way as to generate a sum of 30. After they conducted an experiment and found no right answer, they engaged in a discussion to determine which process they could use to get the right answer. After the discussion, they checked the information they knew from the problem. Based on the knowledge they gained and the other arguments, they decided it was true that A was a set of odd numbers and 30 was an even number. They consequently realized that the set of odd numbers could not generate a sum of even numbers. Their answers are seen in Figure 2.

Translate Version

\begin{tabular}{|c|c|c|c|}
\hline $\begin{array}{c}30 \\
\lambda_{2} 15 \\
115 \\
3,2,3,5\end{array}$ & 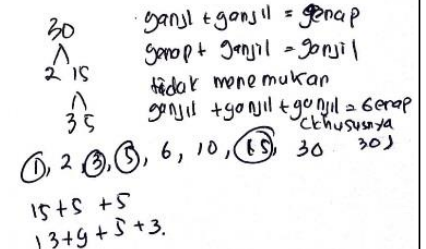 & $\begin{array}{l}\text { } \\
1,2,3,5,6,10,15,30 \\
15+5+5 \\
13+9+5+3\end{array}$ & $\begin{array}{l}\text { Odd }+ \text { odd }=\text { even } \\
\text { Even }+ \text { odd }=\text { even } \\
\text { We can't find the } \\
\text { number in the set A such } \\
\text { that odd }+ \text { odd }+ \text { odd }= \\
\text { even (especially } 30 \text { ) }\end{array}$ \\
\hline
\end{tabular}

Figure 2

One of Eight Samples of the Pre-Service Mathematics Teachers' Answers to Question Number 1

In addition to the two samples of the solution to illogical question number 1, some other samples indicated that the participants deductively proved that the first question was a problem which could not be solved. The deductive analysis was done by assuming the

three members of set A were all odd numbers, i.e., $2 n-1, n \in N$. Furthermore, the preservice teachers summed the three odd numbers, namely,

$\left(2 n_{1}-1\right)+\left(2 n_{2}-1\right)+\left(2 n_{3}-1\right)=2\left(n_{1}+n_{2}+n_{3}\right)-1$, which gave an odd number. Hence, it was not true that the sum of the three numbers was 30 , an even number. Once the pre-service teachers knew that the first problem could not be solved, they sought the lecturer's confirmation and asked whether the problem was actually wrong. The assumption stemmed from the experiment, which implied that the sum of three odd numbers would not result in an even number. In addition, these eight preservice mathematics teachers engaged in a discussion with their peers. During the discussion, the eight participants confirmed their opinion, claiming that it was impossible for all three odd numbers, when summed up, to generate an even number. In this case, truth-seeking and open-mindedness characterised the processes in which both participants engaged. One sample of the participants' answers can be seen in Figure 3. 
Translate Version

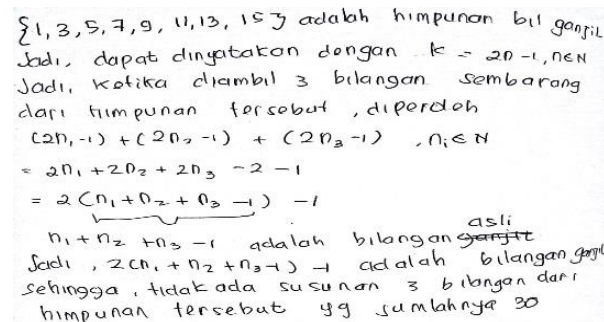

\begin{tabular}{l} 
Translate Version \\
\begin{tabular}{|l|}
\hline \\
$\{1,3,5,7,9,11,13,15\}$ is an odd set. So we can say \\
that $k=2 n-1, n \in N$. So when we get \\
arbitrary 3 number from it set, we get. \\
$\left(2 \mathrm{n}_{1}-1\right)+\left(2 \mathrm{n}_{2}-1\right)+\left(2 \mathrm{n}_{3}-1\right)=2 \mathrm{n}_{1}+2 \mathrm{n}_{2}+2 \mathrm{n}_{3}$ \\
$-2-1=2\left(\mathrm{n}_{1}+\mathrm{n}_{2}+\mathrm{n}_{3}-1\right)-1$ \\
$\left(\mathrm{n}_{1}+\mathrm{n}_{2}+\mathrm{n}_{3}-1\right)$ is a natural number. \\
S $?\left(\mathrm{n}_{1}+\mathrm{n}_{2}+\mathrm{n}_{2}-1\right)-1$ is an ndd numher
\end{tabular} \\
\hline
\end{tabular}

Figure 3

One of Two Samples of the Pre-Service Mathematics Teachers' Answers to Question Number 1

\section{The Truth-Seeking and Open-Mindedness of Pre-Service Mathematics Teachers When Solving Non-Routine Problem Number 2}

Almost all the participants did not investigate the truth behind question number 2 as they worked directly on the given question. Also, 12 participants assumed that the given question was based on truth and had answers that they could find. Based on the analysis of their answers and the video recording, the research participants considered question 2 solvable and believed it had answers that could be revealed. Upon working on the problem, the participants did not investigate the truth behind it and did not search for any evidence or argument to support their answers to it. The lecturer asked them to recheck and discuss their answers. However, the 12 participants did not believe in the other arguments and evidence and continued to assume the question was true. When the interviews were conducted, the participants were asked to explain the reasons and arguments behind each step they took when responding to question number 2 . One of them explained that one step was incorrectly executed. This incorrect step comprised the formulation, $\frac{2 a b-a^{2}-b^{2}}{a^{2}+b^{2}}=\frac{\left(-a^{2}-b^{2}\right)-a^{2}-b^{2}}{2\left(a^{2}+b^{2}\right)}$, while it should have been $\frac{2 a b-a^{2}-b^{2}}{a^{2}+b^{2}} \neq \frac{\left(-a^{2}-b^{2}\right)-a^{2}-b^{2}}{2\left(a^{2}+b^{2}\right)}$. Owing to this assumption, the 12 participants figured out that the given problem was wrong. Although they had established that the problem was wrong, they still thought that checking it was not necessary because their lecturer always gave them correct questions. This finding indicated the behavioural tendencies of not engaging in truth-seeking or demonstrating nnen-mindedness The narticipants' answer is presented in Figure 4.

Translate Version

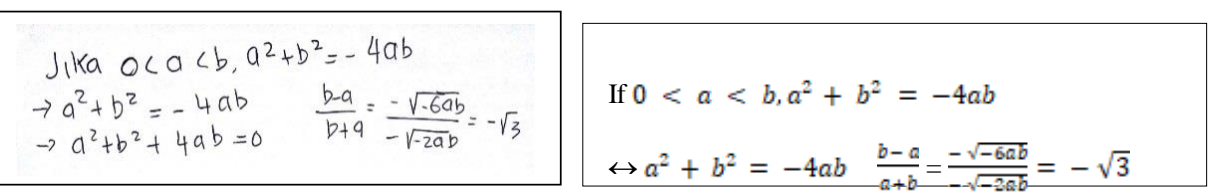

Figure 4

One of Twelve Samples of the Pre-Service Matfinematics ${ }^{2} \mathrm{pl}$ actlpers' Answers to Question Number 2 
The behavioural tendency of the 12 pre-service mathematics teachers was different from that of the others. One participant did not investigate the truth behind the question. However, after going through several processes, they were able to conclude that the problem was wrong. Their conclusion was based on their arguments and the evidence they garnered. The answer indicating this argument is presented in Figure 5.

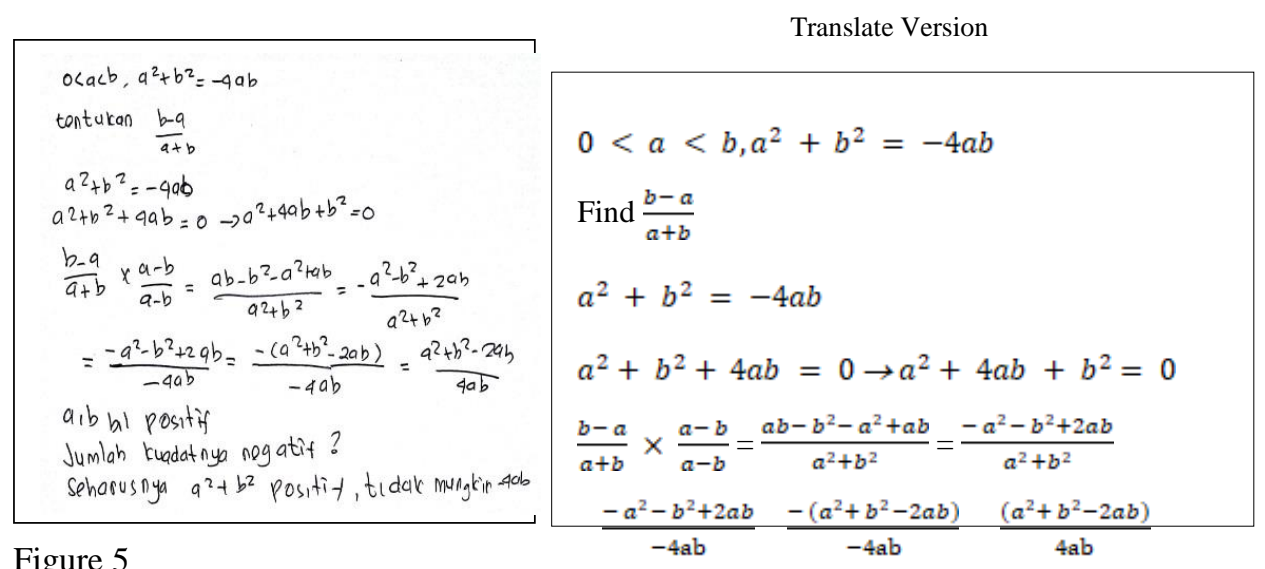

One of Two Samples of the Pre-Service Mathematics Teachers' Answers to Question Number 2

Based on Figure 5, which confirmed the findings from the yideo recording, it was evident that the participants worked directly on the given problem, which required them to change $a^{2}+b^{2}=-4 a c$ to $a^{2}+b^{2}+4 a c=0^{-4 a}$. For this question, the

participants tried to find the value of $a$ and $b$ in such a way as to meet the condition. After examining the problem and discussing it, they assumed that it was incorrect based on the consideration that if $\mathrm{a}$ and $\mathrm{b}$ were real positive numbers, then $a^{2}+b^{2}$ also had to be a positive number. In that case, the number in question could not equal $-4 a b$, where $a b$ was a positive number. Furthermore, another pre-service teacher demonstrated a different tendency from the other 14 participants. He investigated the truth at the beginning, when given question number 2 . The answer to this question is displayed in Figure 6. 
Translate Version

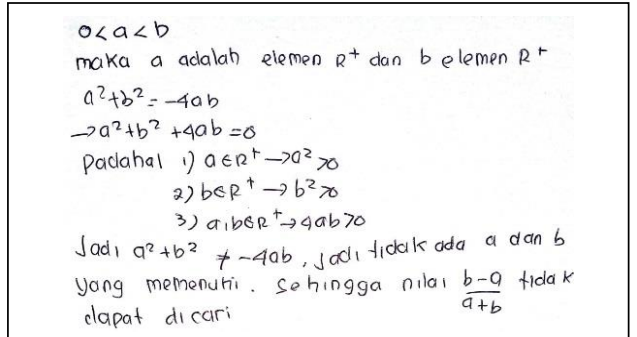

Figure 6

Figure 6

Based on Figure 6 and the results of analysing the video recording, it was implied that this participant investigated the truth by analyzing what was, bnofvinind the pooblem so

that he could say that $a^{2}+b^{2} \neq-4 a b$. In the igefview hequxplained that $a^{2}+b_{b} b^{2}$

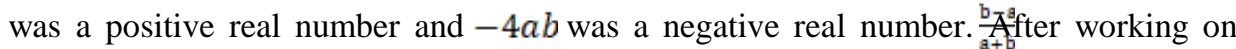
question number 2, the participant decided to ask for the lecturer's confirmation that question number 2 was, in fact, wrong. This was because he was able to figure out the value of $\mathrm{a}$ and $\mathrm{b}$ and prove that the information presented in the question was inaccurate. The behavioural tendency of this participant was to investigate the truth behind the problem before working on it and to accept others' opinions with the corroboration of proven arguments and logical statements.

\section{The Truth-Seeking and Open-Mindedness of Pre-Service Mathematics Teachers When Solving Non-Routine Problem Number 3}

The research participants were given the third non-routine problem, which was incomplete. The problem was stated thus: Find the inverse of the function $f(x)=x^{2}$.

When working on question 3 , none of the participants investigated the truth before responding. In this case, the participants worked directly on the given problem, accepting the condition that a function had an inverse and that the inverse of a function was unique. They did not check and, hence, failed to determine that question number 3

had two possibilities: the possibility that the function $f(x)=x^{2}$ had an inverse and the possibility that it did not. This was actually dependent on the membership requirement

of $x$. However, the interview and video recording corroborated their assumption that, if the membership condition was not written, it was obviously a real number. All the participants understood the agreement well and believed it to be true. During a lecturermediated discussion, the participants still believed in their arguments and evidence, which claimed that $x$ was a member of the real numbers if not listed in the question. This finding revealed that the participants did not engage in a truth-seeking process or show open-mindedness when working on incomplete, non-routine problems. The answer to question number 3 is presented in Figure 7.

International Journal of Instruction, January2019 • Vol.12, No.1 
Translate Version

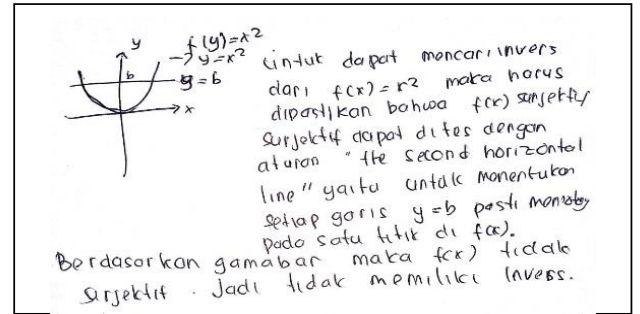

Figure 7

One of Fifteen Samples of the Pre-Service Mathematics Teachers' Answers to Question Number 3.

\section{DISCUSSION}

The research findings provided corroboration that the disposition of critical thinking, especially truth-seeking and open-mindedness, in the solution of the non-routine problem, was not evident in the pre-service mathematics teachers of the Faculty of Teacher Training and Education at the University of Jember. Most of these pre-service teachers were accustomed to assuming that the questions their lecturer gave them were true and that they could answer them easily and directly without investigating the truth behind them. Moreover, they did not attempt to find arguments and other evidence that would convince them that the question given to them was true/accurate or otherwise. These results were in line with the research results of As'ari et al. (2017) and Kurniati \& Zayyadi (2018), who found that the pre-service mathematics teachers in Indonesia were not used to critical thinking because they were classified at the level of non-critical thinkers. The present research also confirmed the results of other studies, evincing that, in general, individuals' truth-seeking and open-mindedness were minimally developed and, in some cases, were entirely non-existent (Akgun \& Duruk, 2016).

The following describes the behavioral tendencies of the pre-service mathematics teachers when solving the illogical and incomplete problems based on the indicators of truth-seeking: (1) they did not investigate the truth before solving the problems (noncritical thinkers and unreflective thinkers), (2) they investigated the truth after solving illogical and incomplete problems (emergent critical thinkers and challenged thinkers), and (3) they investigated the truth while solving the problems (developing critical thinkers and beginning thinkers) (As'ari et al., 2017).

However, the research findings contradicted Ennis's assertion (1996) that a person who thought critically always had the characteristics of critical thinkers, demanding accuracy and analysis as well as an assessment regarding what to do. In this research, the preservice teachers tended not to investigate the truth behind a question given to them before working on it and did not engage in any analysis based on logical verification and argumentation. Thus, the truth-seeking and open-mindedness of the pre-service teachers during their resolution of non-routine questions did not change their positive views and opinions regarding any given problem. 
According to Ajzen (1991), the absence of truth-seeking stemmed from low willingness to behave, which three components, namely, attitude, the subjective norm, and controlled behaviour, influenced. The attitude in question was the attitude of the preservice mathematics teachers, which their experience solving non-routine questions affected. The tendency of pre-service mathematics teachers when solving the nonroutine problem was marked by their ability to solve the only procedural problem by memorizing the formulas and rules required for such problem-solving (Dündar \& Yaman, 2015). Furthermore, one subjective norm that affected the absence of truthseeking was that lecturers did not familiarize students with the solution of non-routine problems in classroom learning (Darby \& Rashid, 2017). Meanwhile, controlled behaviour referred to the pre-service mathematics teachers' perception that non-routine questions were difficult questions that affected their problem-solving behaviour (Dündar \& Yaman, 2015).

The aforementioned discussion points to the urgency surrounding the design of the learning process to focus on the development of pre-service mathematics teachers' critical thinking disposition, especially truth-seeking and open-mindedness. Facilitating this will enable pre-service mathematics teachers to become critical thinkers. There are several ways of developing the critical thinking disposition, including infusion instruction, immersion instruction, and a combination of both (Aizikovitsh-Udi \& Cheng, 2015; Darby \& Rashid, 2017). These methods can also be applied to instruction that focuses on solving non-routine problems as well as traditional learning methods (Temel, 2014).

\section{CONCLUSION}

The present research drew the following conclusions. First, the truth-seeking of the preservice mathematics teachers in the solution of the non-routine problem was characterized by the overlooking of the truth behind the information provided and the tendency to do the given problem directly. The pre-service mathematics teachers only engaged in analysis when they had finished solving the question and had determined that the information in the problem was inaccurate and incomplete. After determining that the information provided in the problem was inaccurate and incomplete, they tended to seek confirmation and discuss it with the others. In this case, almost all of the preservice teachers did not perform truth-seeking when completing non-routine questions. Second, the research revealed that the pre-service mathematics teachers displayed openmindedness when solving non-routine problems as they could accept logical arguments and verification from their peers or lecturer. The open-mindedness encouraged them to think about the non-routine problem-solving process.

With the support of these conclusions, the present study recommends the implementation of continuous mathematics learning which emphasizes the development of critical thinking disposition components, especially truth-seeking and openmindedness. Such learning can be actualized by applying the infusion approach, the immersion approach, a mixed approach, and problem-solving. It can also be actualized by familiarizing pre-service teachers with non-routine questions in all mathematics instruction. 


\section{REFERENCES}

Aizikovitsh-Udi, E., \& Cheng, D. (2015). Developing Critical Thinking Skills from Dispositions to Abilities: Mathematics Education from Early Childhood to High School. Creative Education, 6(4), 455-462. https://doi.org/10.4236/ce.2015.64045.

Ajzen, I. (1991). The Theory of Planned Behavior. Organizational Behavior and Human Decision Processes, 50(2), 179-211.

Akgun, A., \& Duruk, U. (2016). The Investigation of Preservice Science Teachers' Critical Thinking Dispositions in the Context of Personal and Social Factors. Science Education International, 27(1), 3-15.

Akınoğlu, O., \& Karsantık, Y. (2016). Pre-Service Teachers' Opinions on Teaching Thinking Skills. International Journal of Instruction, 9(2), 61-76. https://doi.org/10.12973/iji.2016.925a.

Arsal, Z. (2017). The Impact of Inquiry-Based Learning on The Critical Thinking Dispositions of Pre-Service Science Teachers. International Journal of Science Education, 39(10), 1326-1338. https://doi.org/10.1080/09500693.2017.1329564.

As'ari, A. R., Mahmudi, A., \& Nuerlaelah, E. (2017). Our Prospective Mathematic Teachers are Not Critical Thinkers Yet. Journal on Mathematics Education, 8(2), 145156. https://doi.org/10.22342/jme.8.2.3961.145-156.

Avci, Z. Y., Eren, E., \& Kapucu, M. S. (2016). Practical Tools for Content Development: Pre-Service Teacher Experiences and Perceptions. International Journal of Instruction, 9(2), 19-34. https://doi.org/10.12973/iji.2016.922a.

Aybek, B. (2016). The Relationship between Prospective Teachers' Media and Television Literacy and Their Critical Thinking Dispositions. Eurasian Journal of Educational Research, 63, 261-278. https://doi.org/10.14689/ejer.2016.63.15.

Bakir, S. (2015). Critical Thinking Dispositions of Pre-Service Teachers. Educational Research and Review, 10(2), 225-233. https://doi.org/10.5897/ERR2014.2021.

Biber, A. C., Tuna, A., \& Incikabi, L. (2013). An Investigation of Critical Thinking Dispositions of Mathematics Teacher Candidates. Journal of Educational Research, 4(2), 109-117. Retrieved from http://www.interesjournals.org/ER.

Cheng, M. H. M., \& Wan, Z. H. (2017). Exploring the Effects of Classroom Learning Environment on Critical Thinking Skills and Disposition: A study of Hong Kong 12th Graders in Liberal Studies. Thinking Skills and Creativity, 24, 152-163. https://doi.org/10.1016/j.tsc.2017.03.001.

Choy, S. C., \& Oo, P. S. (2012). Reflective Thinking and Teaching Practices: A Precursor for Incorporating Critical Thinking into the Classroom?. International Journal of Instruction, 5(1), 167-182.

Chukwuyenum, A. N. (2013). Impact of Critical Thinking on Performance in Mathematics among Senior Secondary School Students in Lagos State. IOSR Journal of 
Research \& Method in Education, 3(5), 18-25.

Cooke, A. (2015). Considering Pre-service Teacher Disposition towards Mathematics. Mathematics Teacher Education and Development, 17(1), 1-11.

Darby, N. M., \& Rashid, A. M. (2017). Critical Thinking Disposition: The Effects of Infusion Approach in Engineering Drawing. Journal of Education and Learning, 6(3), 305-311. https://doi.org/10.5539/jel.v6n3p305.

Dilley, A., Kaufman, J. C., Kennedy, C., \& Plucker, J. A. (2015). What We Know About Critical Thinking Part of the 4Cs Research Series. US: Partnership for 21st Century Skills.

Dündar, S., \& Yaman, H. (2015). How do Prospective Teachers Solve Routine and Non-Routine Trigonometry Problems?. International Online Journal of Educational Studies, 7(2), 41-57.

Dwyer, C. P., Hogan, M. J., \& Stewart, I. (2014). An Integrated Critical Thinking Framework for The 21st Century. Thinking Skills and Creativity, 12, 43-52.

Emir, S. (2013). Contributions of Teachers' Thinking Styles to Critical Thinking Dispositions (Istanbul-Fatih Sample). Educational Sciences: Theory \& Practice, 13(1), 337-347.

Ennis, R. H. (1985). A Logical Basis for Measuring Critical Thinking Skills. Educational Leadership, 43(2), 44-48.

Ennis, R. H. (1996). Critical Thinking. United State of America: Prentice-Hall.

Facione, P. A. (2000). The Disposition Toward Critical Thinking: Its Character, Measurement, and Relationship to Critical Thinking Skill. Informal Logic, 20(1), 61-84. https://doi.org/10.22329/il.v20i1.2254.

Golafshani, N. (2003). Understanding reliability and validity in qualitative research. The qualitative report, 8(4), 597-606.

Hocking, I., \& Vernon, D. (2017). The Right Tool for the Right Task: Structured Techniques Prove Less Effective on an Ill-Defined Problem Finding Task. Thinking Skill and Creativity, 26, 84-91. https://doi.org/10.1016/j.tsc.2017.08.001.

Ige, O. A. (2017). Rethinking Students' Dispositions towards Civic Duties in Urban Learning Ecologies. International Journal of Instruction, 10(4), 307-324. https://doi.org/10.12973/iji.2017.10418a.

Insight Assessment. (2017). California Critical Thinking Dispositions Inventory: A Measure of the Critical Thinking Mindset User, User Manual and Resource Guide. (See August, Ed.). San Jose, CA: California Academic Press.

Kalelioğlu, F., \& Gülbahar, Y. (2014). The Effect of Instructional Techniques on Critical Thinking and Critical Thinking Dispositions in Online Discussion. Journal of Educational Technology \& Society, 17(1), 248-258. Retrieved from 
http://www.jstor.org/stable/jeductechsoci.17.1.248.

Karagöl, İ., \& Bekmezci, S. (2015). Investigating Academic Achievements and Critical Thinking Dispositions of Teacher Candidates. Journal of Education and Training Studies, 3(4), 86-92. https://doi.org/10.11114/jets.v3i4.834.

Kurniati, D., \& Zayyadi, M. (2018). The Critical Thinking Dispositions of Students around Coffee Plantation Area in Solving Algebraic Problems. International Journal of Engineering \& Technology, 7(2.10), 18-20.

Lampert, N. (2007). Critical Thinking Dispositions as an Outcome Undergraduate Education. The Journal of General Education, 56(1), 17-33. Retrieved from http://www.jstor.org/stable/27798061.

Nugroho, P. B., Nusantara, T., As'ari, A. R., Sisworo, Hidayanto, E., \& Susiswo. (2018). Critical Thinking Disposition: Students Sceptic in Dealing with Ill-Logical Mathematics Problems. International Journal of Instruction, 11(3), 635-648.

Ohlsson, S. (2012). The Problems with Problem Solving: Reflections on the Rise, Current Status, Possible Future of a Cognitive Research Paradigm. The Journal of Problem Solving, 5(1), 101-128.

Ordem, E. (2017). Developing Critical-Thinking Dispositions in a Listening/Speaking Class. English Language Teaching, 10(1), 50-55.

Rivas, S. F., \& Saiz, C. (2016). The Effects of Teaching Critical Thinking Persist Over Time. Journal of Education and Human Development, 5(1), 240-248.

Stanovich, K. E. (2016). The Comprehensive Assessment of Rational Thinking. Educational Psychologist, 51(1), 23-34.

Temel, S. (2014). The Effects of Problem-Based Learning on Pre-Service Teachers' Critical Thinking Dispositions and Perceptions of Problem-Solving Ability. South African Journal of Education, 34(1), 1 - 20.

Turabik, T., \& Gün, F. (2016). The Relationship between Teachers' Democratic Classroom Management Attitudes and Students' Critical Thinking Dispositions. Journal of Education and Training Studies, 4(12), 45-57. https://doi.org/10.11114/jets.v4i12.1901. 